CASE REPORTS

\title{
Hyperfunctioning carcinoma of the parathyroid gland
}

\author{
T. C. Gale \\ B.S., F.R.C.S., F.R.C.S.Ed., F.R.A.C.S. \\ C. W. I. OWENS \\ B.Sc., M.B., M.R.C.P., Ph.D. \\ Whittington Hospital, Highgate Hill, London, N.19
}

\begin{abstract}
Summary
Carcinoma of the parathyroid gland is rare, constituting about $1 \%$ of most series of patients with hyperparathyroidism. In 1969 a collective review identified forty-six unequivocal cases, and since then a further seven cases have been described in the literature.

A brief review of the condition is presented, and one further case of hyperfunctioning adenocarcinoma of the parathyroid gland is reported in detail. Primary treatment is discussed, together with postoperative biochemical problems, and the therapeutic manoeuvres available to deal with recurrences are presented.
\end{abstract}

\section{Introduction}

Hyperfunctioning carcinoma arising in the parathyroid gland is rare, as shown by the last extensive review of the subject (Holmes et al., 1969). At that time only forty-six cases were considered to fulfil the required criteria, and since then only seven further cases (Mansour \& Letton, 1967; Kelly, 1969; Newton \& Sumich, 1968a; Saunders, 1970; Singer et al., 1970; Sherif et al., 1970; Rossi et al., 1971), have been described in the English language medical literature. Carcinoma accounts for approximately $0.5-1 \%$ of cases of primary hyperparathyroidism (Pyrah et al., 1966) and presents a metabolic rather than a neoplastic threat to life before excision, and a stormy postoperative period afterwards, but the response to effective treatment is rewarding. A brief review is presented together with a case history highlighting many of the management problems.

\section{Case report}

Mrs P. V., a 43-year-old Cypriot, was referred by her general practitioner complaining of muscle pain in the arms and legs, unaffected by exercise, noted for 8-9 months and worse for 10 weeks. She had noted loss of her appetite and of 1 st in weight over 10 weeks, and vomiting after food for 4 weeks. There was dysphagia, with a sensation of solid food sticking in the throat about the level of the thyroid gland. There was no definite history of polydipsia or polyuria, but there was an inability to sleep due to a dry mouth. There was no relevant past medical history, or family history.

On examination she was apparently in a severe, agitated anxiety state. In the neck there was a mobile, spherical, firm, non-cystic, non-tender nodule about $2 \mathrm{~cm}$ in diameter closely connected with the left lobe of the thyroid gland, but not obviously adherent to adjacent tissues. There was no cervical lymphadenopathy. Indirect laryngoscopy showed both vocal cords moved normally. She had minimal bilaterad medial corneal calcification. There was no bony teno derness, no muscle tenderness or wasting, no limita tion of joint movement, and no obvious abnormalif ties in the cardio-vascular, respiratory, lymphatic or central nervous system. Blood pressure 140/70 $\mathrm{mmHg}$, pulse rate $100 / \mathrm{min}$, sinus rhythm.

Laboratory investigations: $\mathrm{Hb} 76 \%$, ESR $73 \mathrm{~mm} /$ hr $(35 \mathrm{~mm} / \mathrm{hr} 1$ month previously in OPD) WBC 7900 , differential normal. Plasma urea $54 \mathrm{mg} / 100$ $\mathrm{ml}$; bicarbonate $21 \mathrm{mEq} / 1$, chloride $99 \mathrm{mEq} / 1$, fasting calcium (not corrected) 15.2 and $17 \cdot 1 \mathrm{mg} / 100 \mathrm{ml}$, phosphate $2.9 \mathrm{mg} / 100 \mathrm{ml}$, alkaline phosphatase 28 KAU, 24-hr urine $(1700 \mathrm{ml})$ calcium $290 \mathrm{mg}$, phosphate $460 \mathrm{mg}$. Creatinine clearance $33 \mathrm{ml} / \mathrm{min}$. Faecal fat $2.5 \mathrm{~g} /$ day. Thyroid scan normal, PBI 5.4 $\mu \mathrm{g} / 100 \mathrm{ml}, 48-\mathrm{hr}$ uptake $31 \%$ (normal $25-55 \%$ ) T3 uptake $94 \%$ (normal $92-125 \%$ ). Total serum protein $6.8 \mathrm{~g} / 100 \mathrm{ml}$, albumin $4.4 \mathrm{~g} / 100 \mathrm{ml}$, strip normal. ECG: ST interval $0.08 \mathrm{sec}$. Hydrocortisone, $40 \mathrm{mg}$ 8-hourly, failed to suppress serum calcium level below $15.4 \mathrm{mg} / 100 \mathrm{ml}$ (SG 1027). X-ray changes typical of hyperparathyroidism were seen in the hands, skull and teeth, and there were bilateral renal calculi. The chest X-ray and barium meal were normal.

Operation. On surgical exploration of the neck (Mr J. M. Davis, Whittington Hospital) under $240 \mathrm{mg}$ hydrocortisone cover because of the recent suppression test, a tumour mass was found situated behind and adherent to the left upper pole of the 
thyroid gland, and closely adherent to the oesophagus. No regional lymph nodes were palpably involved. Two normal parathyroid glands were identified on the right, the lower parathyroid on the left was not identified. A left hemithyroidectomy was performed, including sharp dissection down to the oesophageal mucosa. Macroscopically the tumour was a hard, well circumscribed pale grey mass $4 \times 2 \times 2 \mathrm{~cm}$, weight $10 \mathrm{~g}$. Microscopic examination showed a well differentiated adenocarcinoma of the parathyroid gland with local invasion into the thyroid gland, and also into the oesophageal muscle. Malignant cells were seen in neighbouring lymphatic vessels.

Postoperative management. The plasma calcium fell steadily to $8.6 \mathrm{mg} / 100 \mathrm{ml}$ by the fourth postoperative day when the patient experienced tingling with weakness in the arms and legs and mental confusion. Carpo-pedal spasm was marked but Chvostek's sign was negative. Initially this was relieved with $20-40 \mathrm{ml} 10 \%$ calcium gluconate by slow intravenous injection on several occasions, but by the eighth day the weakness was severe, laryngeal stridor was present and spasm of the back, arm and leg muscles was marked. In contrast to her initial postoperative lethargy the patient was extremely agitated and restless. $60 \mathrm{ml}$ of $10 \%$ calcium gluconate i.v. only partially relieved the tingling and stridor, but there was no other improvement. However, $15 \mathrm{~min}$ after $4 \mathrm{ml} 50 \%$ magnesium sulphate i.m. (serum magnesium $1.6 \mathrm{mg} / 100 \mathrm{ml}$ at this time, but level not available during the attack) there was clear improvement, with abolition of the tingling, relaxation of muscle spasm and distinct calming and re-orientation. Chvostek's sign remained negative until the eleventh postoperative day (calcium $8.0 \mathrm{mg} / 100 \mathrm{ml}$, phosphate $3.5 \mathrm{mg} / 100 \mathrm{ml}$, phosphatase $72 \mathrm{KAU}$ ) and then remained positive until the thirty-second day when increased oral calcium and Maalox (magnesium aluminium hydroxide) had elevated the serum calcium to $8.5 \mathrm{mg} / 100 \mathrm{ml}$ and phosphate to $3.1 \mathrm{mg} /$ $100 \mathrm{ml}$ (Fig. 1). The patient was discharged home after $\mathbf{4 2}$ days, and subsequently received a course of super-voltage radiotherapy (Dr J. N. Godlee, University College Hospital, London) to her neck and mediastinum, with a total dose of $5400 \mathrm{rad}$ over 5 weeks. She continued to take a low phosphate diet, effervescent calcium $6 \mathrm{~g}$ four times a day, Maalox $15 \mathrm{ml}$ 6-hourly, and AT $10(0.25 \mathrm{mg} / \mathrm{ml}) 5$ $\mathrm{ml}$ 8-hourly for 6 weeks, but then she chose to cease medication. Six weeks later she again developed tetany, which responded to DHT $1 \mathrm{mg} /$ day. Investigations at that time were as follows: $\mathrm{Hb} 10.5 \mathrm{~g} / 100$ $\mathrm{ml}$; ESR $25 \mathrm{~mm} / \mathrm{hr}$; plasma calcium $6.4 \mathrm{mg} / 100 \mathrm{ml}$ (SG 1025-6); phosphate $4.8 \mathrm{mg} / 100 \mathrm{ml}$; alkaline phosphatase $14 \mathrm{KAU}$; magnesium $1.63 \mathrm{mg} / 100 \mathrm{ml}$; urea $67 \mathrm{mg} / 100 \mathrm{ml}$; sodium $140 \mathrm{mEq} / 1$; potassium
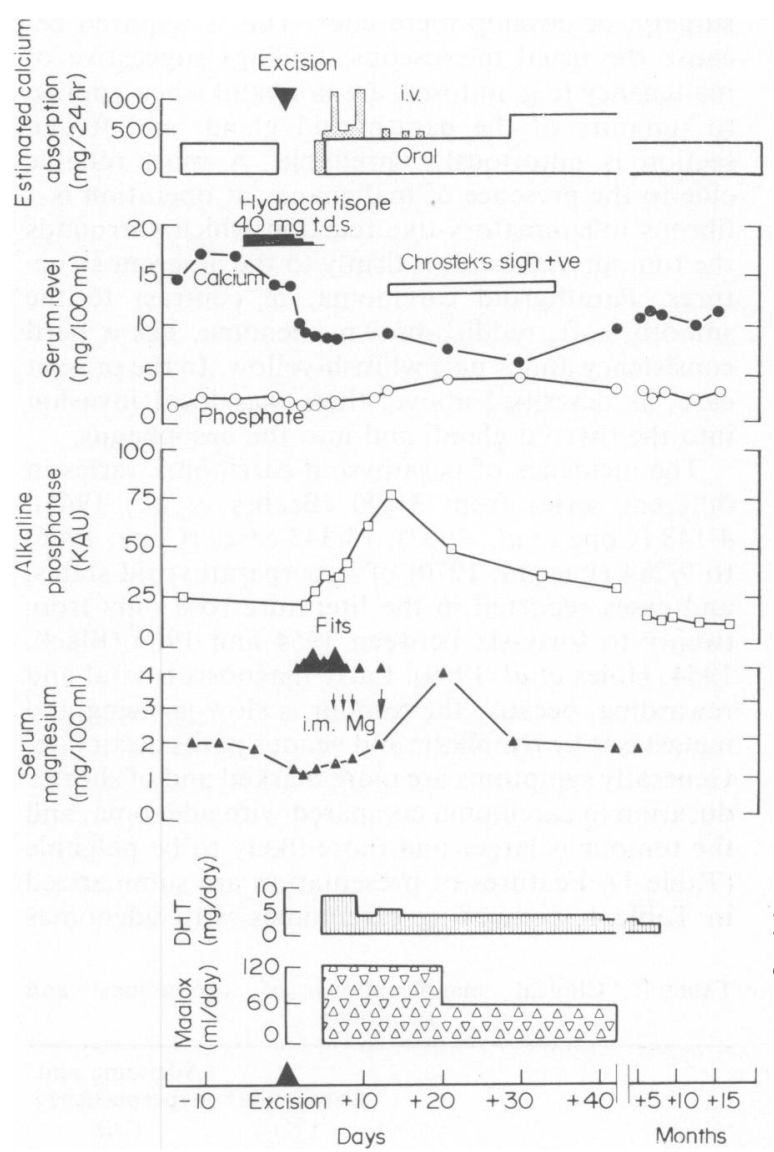

FIG. 1. The course and management of a case of parathyroid carcinoma (Mrs. P. V., aet 43).

$4.4 \mathrm{mEq} / \mathrm{l}$; chloride $103 \mathrm{mEq} / 1$; bicarbonate 22 $\mathrm{mEq} / 1$. 24-hr urinary calcium $33 \mathrm{mg}$; phosphate $1034 \mathrm{mg}$; magnesium $82 \mathrm{mg}$.

\section{Discussion}

Because definitely invasive tumours of the parathyroid gland are rare, stringent criteria have been established to make the diagnosis of carcinoma, in order to differentiate from adenoma and hyperplasia (Holmes et al., 1969; Black, 1954; Cope et al., 1953; Kelly, 1969). The electron microscope has demonstrated ultra-structural differences (Faccini, 1970). These criteria vary with different authors but in general the following are accepted:

(1) The tumour must be biochemically hyperfunctioning. This is a requirement because of the similar histological appearance of various thyroid and thymic tumours, and pathological lymph nodes, to that of carcinoma of the parathyroid.

(2) The tumour must be locally invasive, or have local or distant metastases at the time of the original 
surgery, or develop them later. This is required because the usual microscopic findings suggestive of malignancy (e.g. mitoses) are not valid when applied to tumours of the parathyroid gland, and frozen section is notoriously unreliable. A most reliable clue to the presence of malignancy at operation is a fibrous inflammatory-like reaction which surrounds the tumour and binds it firmly to the adjacent structures. Parathyroid carcinoma, in contrast to the smooth, soft, reddish-brown adenoma, has a hard consistency and is pale whitish-yellow. In the present case, as described above, there was local invasion into the thyroid gland, and into the oesophagus.

The incidence of parathyroid carcinoma varies in different series from $3 / 400$ (Beahrs et al., 1963), 4/148 (Cope et al., 1953), 15/343 cases (Cope, 1966) to $9 / 284$ (Faccini, 1970) of hyperparathyroid states, and cases reported in the literature rose only from twenty to forty-six between 1954 and 1969 (Black, 1954, Holes et al. 1969). Early diagnosis is vital and rewarding, because the tumour is slow-growing and metastases by lymphatic and venous paths occur late. Generally symptoms are more marked and of shorter duration in carcinoma compared with adenoma, and the tumour is larger and more likely to be palpable (Table 1). Features of presentation are summarized in Table 1, comparing carcinomas with adenomas

TABle 1. Clinical manifestations of carcinomas and adenomas

\begin{tabular}{lcc}
\hline & $\begin{array}{c}\text { Carcinoma* } \\
(\%)\end{array}$ & $\begin{array}{c}\text { Adenoma and } \\
\text { hyperplasiał } \$ \\
(\%)\end{array}$ \\
\hline Calcium: & 82 & 50 \\
$\quad$ More than $13 \mathrm{mg} / 100 \mathrm{ml}$ & 6 & 50 \\
$\quad$ Less than $12 \mathrm{mg} / 100 \mathrm{ml}$ & 73 & $30-54$ \\
Bone disease & 52 & 14 \\
Palpable neck mass & 15 & 2 \\
Pancreatitis & 32 & - \\
Metastases: & 16 & - \\
$\quad$ Local (neck) & 52 & - \\
Distant (e.g. lung) & $1: 1$ & F $3-6: 1$ \\
Cervical recurrence & & \\
Sex preponderance &
\end{tabular}

\footnotetext{
* From Table 2, and Holmes et al. (1969).

† Pyrah et al. (1966).

$\mp$ Black, B.M. (1958).

$\S$ Reinhoff et al. (1968).
}

and hyperplasia, showing the higher calcium levels, increased incidence of bone disease, pancreatitis, and of the presence of a palpable neck-mass in carcinomas, and the lack of a female sex preponderance. The age of incidence is between 12 and 72 years, with $60 \%$ of carcinomas between 40 and 50 years compared with only $21 \%$ of the adenomas. An associated laryngeal nerve palsy is strongly suggestive of malignancy.
In the eight cases (including the present case) reported in the literature since the last collective review, six were female, five had radiological changes, six had evidence of local invasion and five renal tract involvement. (Table 2). Cases may present, as here, with manifestations of neoplasia, i.e. tumour and dysphagia caused by direct oesophageal infiltration, or with clinical features of hypercalcaemia, e.g. psychiatric features of 'neurosis'. This in a patient unable to speak English, provided yet another example of 'metabolic madness' (Watson, 1968; Anderson, 1968; Peterson, 1968). Another feature was thirst, only partially relieved by repeated small drinks and yet sufficient to prevent sleep. It was not accompanied by polyuria (urine volume $1-1 \frac{1}{2} 1 / 24$ hr), thus suggesting that hypercalcaemia may stimulate thirst directly rather than cause a diuresis with secondary polydipsia.

The frequently stormy postoperative course of these patients follows the sudden withdrawal of hormone excess causing decreased calcium absorption and phosphate loss with resulting depression of calcium. The situation will be further aggravated with any pre-existing negative calcium and magnesium balance which is associated with the bone disease of primary hyperparathyroidism (Bulgar \& Gusmann, 1933; Tibbets \& Aub, 1937; Barnes et al 1957) and by phosphate retention related to the frequently associated renal failure. Normal parathyroid function may remain repressed from the effects of surgical trauma and the hyperfunctioning tumour (Ellis \& Barr, 1951) and accelerated uptake of calcium and magnesium into the bones may finally precipitate tetany, convulsions occasionally with fractures of weakened bones (Davies \& Friedman, 1966), or even death (Nicholson, 1969). The maximum danger is between the fourth and tenth day, and the patient and nursing staff should be warned of the significance of tingling or muscle twitching.

The patient's condition is best monitored with daily estimation of fasting levels of calcium (corrected for serum SG) and magnesium, if possible. Chvostek's sign, although a clinical guide is not an adequate indicator of the patient's well-being. It can be positive with normal serum levels of calcium and magnesium (Dent, 1962), may be positive following parathyroidectomy irrespective of calcium values (Hanna et al., 1960) and occasionally intravenous calcium gluconate will correct a hypocalcaemia without reversing an associated positive sign (Newton \& Sumich, 1968b). Both the latter authors suggest hypomagnesaemia is an important consideration.

Hypocalcaemia and hypomagnesaemia should be promptly corrected, as above, with appropriate parenteral supplements, but with marked renal failure urinary magnesium clearance is reduced and 


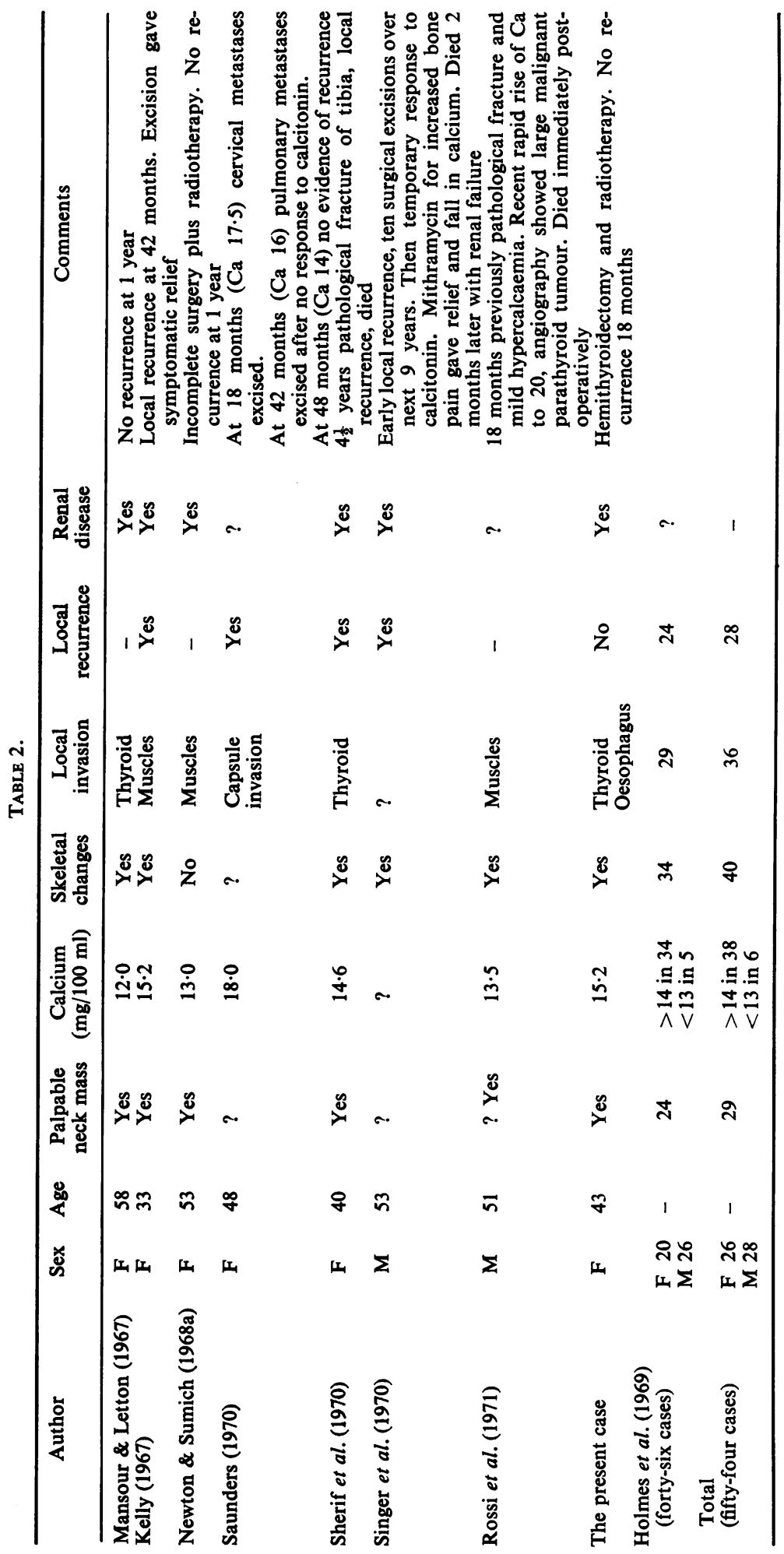


repeated i.m. magnesium should be given with care. Signs of intoxication include cerebral and neuromuscular depression with feelings of thirst and heat, the appropriate antidote being intravenous calcium gluconate. Biochemical estimation provides the only definitive assessment but deficiency may be suspected on physiological grounds. Low calcium and magnesium states increase muscular and neural irritability, but whereas hypomagnesaemia increases acetylcholine release, hypocalcaemia decreases it and slows neuromuscular transmission. This may explain why there is no tetany per se in hypomagnesaemia (Hanna, 1960; McIntyre, 1963) and Trousseau's sign is negative but Chvostek's sign is positive (Newton \& Sumich, 1968b). Convulsions and psychiatric features, e.g. agitation and aggression (Davies \& Friedman, 1966; Nicholson, 1969) occur in calcium and magnesium deficiency but tremor is less common in hypocalcaemia.

Postoperative vitamin D (preferably as pure DHT) should be given routinely as $8 \mathrm{mg}, 8 \mathrm{mg}, 4 \mathrm{mg}, 4 \mathrm{mg}$, $2 \mathrm{mg}, 2 \mathrm{mg}$, on successive days with intravenous calcium as necessary. Excess vitamin $\mathbf{D}$ was used in this case to overcome the more resistant postoperative tetany found when mild renal failure antagonises the action of vitamin D (Rasmussen, 1968). Up to $10 \mathrm{mg}$ daily vitamin $\mathrm{D}$ can be used before operation if resistant hypocalcaemia is anticipitated. Milk though convenient is an inefficient calcium supplement because of the high phosphate content, but absorption can be increased by giving up to 40 $\mathrm{ml}$ daily Aludrox (aluminium hydroxide) in divided doses to chelate the phosphate. In this present case Maalox (containing magnesium and aluminium hydroxide) was used. Low phosphate diets may also increase the serum calcium by less well understood mechanisms.

Close follow-up must continue until bone healing is complete and ideally until the serum calcium is stable. If rarefaction is demonstrated radiologically then at least half of the mineral is lost (Lachman, 1955) and needs replacement. Alkaline phosphatase activity is a good index of bone activity during the healing or 'bone-sucking' phase (Potts \& Roberts, 1958).

In the treatment of this malignant tumour, most authors advise radical excision, including hemithyroidectomy and neck dissection to include especially the nodes in the tracheo-oesophageal groove (Hoehn, Beahrs \& Woolner, 1969; Castleman, 1952) because of the great tendency towards local invasion. Radiotherapy used as an adjunct to operative measures is largely unsatisfactory, although there are a "few" reports of reduction in tumour size or serum calcium levels.

The optimal treatment of recurrence is not clear. Multiple excisions of cervical recurrences, charac- teristic of this disease, generally result in reduction of the serum calcium level and hence facilitate the management of metabolic disturbances. Similarly resection of functioning pulmonary metastases should be considered as a palliative procedure. (Saunders, 1970; Holmes et al., 1969). Oestrogens have also provided some temporary palliative benefit (Goepfert et al., 1966; Ellis \& Barr, 1951). Porcine calcitonin has been used with variable success (Saunders, 1970; Pak et al., 1968), in one case serum calcium was reduced temporarily from 16 to $15 \mathrm{mg}$ / $100 \mathrm{ml}$ but in another case there was marked reduction of serum calcium for several months. Complete restoration to normal would be unexpected since calcitonin possibly only antagonises the action of parathormone on bone, and not that on the gut and kidneys which probably also contributes to sustained hypercalcaemia (MacIntyre, 1970; Foster, 1968). Mithramycin, a cytotoxic antibiotic, has successfully lowered serum calcium levels in similar clinical situations (Singer et al., 1970). It is important to reemphasize that the present treatment of choice is surgical removal of the neoplastic tissue wherever possible.

Prognosis should be guarded, though initially optimistic, because times of recurrence vary from 3 months to 9 years (Holmes et al., 1969; Hoehn एक al., 1969). Holmes had forty-three patients followed. up for up to 12 years when $65 \%$ had died, $11 \%$ ha $\Phi$ recurrence, giving an overall cumulative survival rate of $50 \%$ at 5 years and $13 \%$ at 10 years, a mean survival of 4 years. Our patient has been followed for 18 months without evidence of recurrence (although the serum calcium is slowly rising). Three of the most recently published cases have been followed for less than 18 months, all are without signs of recurrence. Another case, alive after 6 years developed a cervical lymph gland metastasis after 18 months (excised) and 2 years later pulmonary metastases which, after porcine calcitonin treatment had failed, were excised with further metabolic remission.

\section{Acknowledgments}

We wish to thank Mr J. M. Davis for permission to publish details of this patient, Dr J. N. Godlee who arranged radiotherapy, and Dr L. C. A. Watson for providing biochemical follow-up data, together with encouragement and advice in the preparation of this paper.

\section{References}

Anderson, J. (1968) Psychiatric aspects of primary hyperparathyroidism. Proceedings of the Royal Society of Medicine, 61, 1123.

Barnes, B.A., Krane, S.M. \& Cope, O. (1957) Magnesium studies in relation to hyperparathyroidism. Journal of Clinical Endocrinology, 17, 1407.

Beahrs, O.H., Angelos, P.S. \& Woolner, L.B. (1963) Carcinoma of the parathyroid gland: Report of a case. Surgical clinics of North America, 43, 1123. 
BlACK, B.K. (1954) Carcinoma of the parathyroid. Annals of Surgery, 139, 355.

BLACK, B.M. (1958) Tumours of the parathyroid glands, primary hyperparathyroidism. American Journal of Surgery, 95, 395.

Bulger, H.A. \& GausmanN, F. (1933) Magnesium metabolism in hyperparathyroidism. Journal of Clinical Investigation, 12, 1135.

Castleman, B. (1952) Tumours of the parathyroid gland. In: Atlas of Tumour Pathology, Sec. IV, Fasc. 15, p. 50. Armed Forces Institute of Pathology, Washington D.C.

COPE, O. (1966) The story of hyperparathyroidism at the Massachusetts General Hospital. New England Journal of Medicine, 274, 1174.

Cope, O., Nardi, G.L. \& Castleman, B. (1953) Carcinoma of the parathyroid gland: Four cases among 143 patients with hyperparathyroidism. Annals of Surgery, 138, 661.

Davies, D.R. \& Friedman, M. (1966) Complications after parathyroidectomy-Fractures from low calcium and magnesium convulsions. Journal of Bone and Joint Surgery, 48B, 117.

DENT, C.E. (1962) Some problems of hyperparathyroidism. British Medical Journal, 2, 1419.

Ellis, J.T. \& BARR, D.P. (1951) Metastasizing carcinoma of the parathyroid gland with osteitis fibrosa cystica and extensive calcinosis. American Journal of Pathology, 27, 383.

FACciNI, J.M. (1970) The ultra-structure of parathyroid glands removed from patients with primary hyperparathyroidism: A report of forty cases, including four carcinomata. Journal of Pathology, 102, 189.

Foster, G.V. (1968) Calcitonin: A review of experimental and clinical investigations. Postgraduate Medical Journal, 44, 411.

Goepfert, H., Smart, C.R. \& Rochlin, D.B. (1966) Metastic parathyroid carcinoma and hormonal chemotherapy. Annals of Surgery, 164, 917.

Hanna, S., Harrison, M., Macintyre, I. \& Frazer, R. (1960) The syndrome of magnesium deficiency in man. Lancet, ii, 172.

Hoenn, J.G., Beahrs, O.H. \& Woolner, L.B. (1969) Unusual surgical lesions of the parathyroid gland. American Journal of Surgery, 118, 770.

Holmes, E.C., Morton, D.L. \& Ketcham, A.S. (1969) Parathyroid carcinoma: A collective review. Annals of Surgery, 169, 631.

Kelly, T.R. (1969) Parathyroid carcinoma: A case report and review of the literature. American Surgeon, 35, 374.

LACHMANN, E. (1955) Osteoporosis: The potentialities and limitations of its roentgenologic diagnosis. American Journal Roentgenology, 74, 712.

MACINTYRE, I. (1963) An outline of magnesium metabolism in health and disease. Journal of Chronic Diseases, 16, 201.
Macintyre, I. (1970) Discussion (vide Saunders, 1970). Proceedings of the Royal Society of Medicine, 63, 454.

Mansour, K.A. \& LetTon, A.H. (1967) Adenocarcinoma of the parathyroid gland: Review of the literature and report of a case. American Surgeon, 33, 378.

Newton, N.C. \& Sumich, M.G. (1968a) Hyperfunctioning parathyroid carcinoma. Medical Journal of Australia, 2, 219.

Newton, N.C. \& Sumich, M.G. (1968b) Chvostek's sign, hypomagnesaemia and behavioral disturbance after parathyroid adenomectomy. Medical Journal of Australia, 2, 394.

Nicholson, W.F. (1969) Results of parathyroidectomy. British Journal of Surgery, 56, 106.

Pak, C.Y.C., Wills, M.R., SMith, G.W. II \& BartTer, F.C. (1968) Treatment with thyrocalcitonin of the hypercalcaemia of parathyroid carcinoma. Journal of Clinical Endocrinology, 28, 1657.

Petersen, P. (1968) Psychiatric disorders in primary hyperparathyroidism. Journal of Clinical Endocrinology, 28, 1491.

Pollack, S., Goldin, R.R. \& Cohen, M. (1961) Parathyroid carcinoma: Report of two cases and review of the literature. Archives of Internal Medicine, 108, 583.

Potts, J.T. \& Roberts, B. (1958) Clinical significance of magnesium deficiency and its relation to parathyroid disease. American Journal of Medical Science, 235, 206.

Pyrah, L.N., Hodgkinson, A. \& Anderson, C.K. (1966) Primary hyperparathyroidism-A critical review. British Journal of Surgery, 53, 245.

RASMUSSEN, H. (1968) In: Textbook of Endocrinology (Ed. by R. H. Williams), 4th edn, p. 943. Saunders, Philadelphia.

RIENHOFF, W.F. JR, RIENHOFF, W.F. III, BRAWLEY, R.K. \& Shelley, W.M. (1968) The surgical treatment of hyperparathyroidism. Annals of Surgery, 168, 1061.

Rossi, P., Carillo, F.J. \& Johnstone, B. (1971) Angiography in the diagnosis of parathyroid carcinoma. New England Journal of Medicine, 284, 198.

SAUNDERS, K.B. (1970) Carcinoma of parathyroid-case report. Proceedings of the Royal Society of Medicine, 63, 453.

Sherif, M., El-Bol.kainy, N. \& Khatter, H. (1970) Carcinoma of the parathyroid gland; case report and review of literature. Journal of Egyptian Medical Association, 53, 71.

Singer, F.R., NeEr, R.M., Murray, T.M., Keutmann, H.T., Deftos, L.J. \& PotTs, J.T. JR (1970) Mithramycin for intractable hypercalcaemia due to parathyroid carcinoma. New England Journal of Medicine, 283, 634.

TinbetTs, D.M. \& AUB, J.C. (1937) Magnesium metabolism in health and disease. II. The effect of the parathyroid hormone. Journal of Clinical Investigation, 16, 503.

WATSON, L. (1968) Clinical aspects of hyperparathyroidism. Proceedings of the Royal Society of Medicine, 61, 1123. 